\title{
Comparative Evaluation of Casein Phosphopeptide-
} Amorphous Calcium Phosphate-Fluoride Paste and Sodium Fluoride Mouthwash in the Prevention of Dental Erosion: An

\section{In Vitro Study}

\author{
Beulah M Bejoy ${ }^{1}$, Moonnamkoottu S Sruthi ${ }^{2}$, Liza George ${ }^{3}$, Josey Mathew ${ }^{4}$, Raveendran PV Vineet ${ }^{5}$, Aleesha Joy ${ }^{6}$
}

\begin{abstract}
Aim: To compare the efficacy of casein phosphopeptide-amorphous calcium phosphate-fluoride (CPP-ACP-F) paste and $0.2 \%$ sodium fluoride mouthwash in the prevention of dental erosion using profilometer.

Materials and methods: The buccal surfaces of 36 premolar sound teeth were ground and polished to achieve a flat surface with silicone disks. Samples were allocated in three groups randomly. Group I was pretreated for 5 days four times a day with CPP-ACP-F paste. Group II was pretreated for 5 days with $0.2 \%$ sodium fluoride mouthwash four times a day. Group III remained as the control group without any pretreatment. In the next step, all the samples were exposed four times a day for 3 days to carbonated beverages. The samples were rinsed with saline after each erosive cycle and stored in artificial saliva. The profilometer was used to determine the surface loss. The data collected were evaluated using one-way analysis of variance (ANOVA) along with post hoc test.

Results: The erosion of group I (CPP-ACP-F paste) and group II ( $0.2 \%$ sodium fluoride mouthwash) was significantly less than that of group III (control group). The erosion in group II was significantly lower than in group I.

Conclusion: Both sodium fluoride mouthwash and CPP-ACP-F paste are effective in the prevention of dental erosion. Sodium fluoride mouthwash shows higher reduction in dental erosion when compared with CPP-ACP-F paste.

Clinical significance: This study contributes to the understanding of the efficacy of CPP-ACP-F paste and $0.2 \%$ sodium fluoride mouthwash in the prevention of dental erosion.

Keywords: Casein phosphopeptide-amorphous calcium phosphate-fluoride, Dental erosion, Laboratory research, Profilometer, Sodium fluoride. The Journal of Contemporary Dental Practice (2020): 10.5005/jp-journals-10024-2776
\end{abstract}

\section{INTRODUCTION}

Dental erosion is the loss of dental hard tissue, which is caused by sustained direct contact of extrinsic or intrinsic acids with tooth surfaces that are not produced by bacteria. ${ }^{1,2}$ The etiology of dental erosion is multifactorial and can be from intrinsic (often due to gastroesophageal reflux, bulimia, and rumination) or extrinsic sources (diet, particularly soft drinks; acidic medications; and industrial or environmental chemicals). ${ }^{3}$ Beyond esthetic consequences and associated oral health issues, erosive activity leading to the exposure of the dentin can result in hypersensitivity and pulp exposure which have been suggested as direct clinical outcomes of erosion. ${ }^{4}$ Clinically, this is seen as porosities in dentin surrounded by a prominent enamel margin. ${ }^{5}$

A thorough understanding of etiology and early recognition of signs and symptoms are crucial for the effective management of dental erosion. Preventive measures include those capable of avoiding or reducing direct contact with acids, increasing the acid resistance of hard dental tissues, and minimizing abrasion by toothbrushing. The role of fluoride-containing solutions and varnishes as well as casein, calcium, and phosphate-containing compounds (CPP-ACP) in preventing and reducing erosive wear has been evaluated in various studies. ${ }^{6,7}$ Casein phosphopeptideamorphous calcium phosphate-fluoride has also been turned out to be a promising treatment modality in the prevention of dental erosion. This study was conducted to compare the efficacy of casein phosphopeptide-amorphous calcium phosphate-fluoride

\begin{abstract}
${ }^{1-6}$ Department of Conservative Dentistry and Endodontics, Annoor Dental College and Hospital, Perumattom, Muvattupuzha, Kerala, India Corresponding Author: Beulah M Bejoy, Department of Conservative Dentistry and Endodontics, Annoor Dental College and Hospital, Perumattom, Muvattupuzha, Kerala, India, Phone: +91 9747656740, e-mail: beulahbejoy91@gmail.com

How to cite this article: Bejoy BM, Sruthi MS, George L, et al. Comparative Evaluation of Casein Phosphopeptide-Amorphous Calcium Phosphate-Fluoride Paste and Sodium Fluoride Mouthwash in the Prevention of Dental Erosion: An In Vitro Study. J Contemp Dent Pract 2020;21(3):267-270.
\end{abstract}

Source of support: Nil

Conflict of interest: None

(CPP-ACP-F) paste and $0.2 \%$ sodium fluoride mouthwash both containing $900 \mathrm{ppm}$ fluoride content in the prevention of artificially induced erosive lesions in human teeth using profilometer.

\section{Materials and Methods}

The study was conducted in the Department of Conservative Dentistry and Endodontics, Annoor Dental College and Hospital, Muvattupuzha, and in Sree Chitra Tirunal Institute for Medical Sciences and Technology, Thiruvanananthapuram. A total of 36 sound intact human premolar teeth which were extracted 
for orthodontic treatment were selected for the study. The teeth were disinfected with $6 \%$ hydrogen peroxide and stored in saline. The buccal surfaces of 36 premolar sound teeth were ground and polished to achieve a flat surface with silicone disks. The surfaces were then rinsed with saline and placed in $17 \%$ ethylenediaminetetraacetic acid solution for 1 minute for smear layer removal. The samples were then rinsed again with saline. Half the tooth surfaces were covered with adhesive tape (Fig. 1), and the samples were divided into three groups, namely I, II, and III, at random with 12 samples in each group and were stored in artificial saliva (consisting of sodium carboxy methyl cellulose, $2 \mathrm{~g} / \mathrm{L}$; potassium chloride, $1.40 \mathrm{~g} / \mathrm{L}$; sodium phosphate, $0.80 \mathrm{~g} / \mathrm{L}$; sodium bicarbonate, $0.50 \mathrm{~g} / \mathrm{L}$; calcium chloride, $0.44 \mathrm{~g} / \mathrm{L}$; magnesium chloride, $0.06 \mathrm{~g} / \mathrm{L}$; and sufficient quantity of distilled water and phosphoric acid to adjust the $\mathrm{pH}$ to 6.4). This solution was prepared in the Department of Biochemisty, M. A. College, Kothamangalam.

Groups I and II received pretreatment before being placed in acid solution (Fig. 2). Based on the manufacturer's instructions, CPP-ACP-F paste [Tooth Mousse (TM) Plus; GC, Japan] was applied on each sample four times a day (5 minutes each time) for 5 days. In group II, the samples were placed four times a day (1 minute each time) for 5 days in $0.2 \%$ sodium fluoride mouthwash (Sensodent $\mathrm{K}$; Indoco Remedies Ltd, Mumbai, India) as instructed by the manufacturer (Fig. 3). The teeth were irrigated with saline after each pretreatment phase and stored in artificial saliva until the next phase. The samples from group III were not pretreated and stored in artificial saliva. The teeth in all the three groups were exposed to acid solution after completion of the pretreatment phase. The samples were placed four times a day ( 2 minutes each time) for 3 days in a glass of carbonated beverages (Pepsi; PepsiCo, Inc., New York; Fig. 4). Samples were rinsed with saline after each phase and stored in artificial saliva until the next phase of the test.

The adhesive tape was removed from all the samples in the next phase. Profilometry was performed for the protected (reference surface) and eroded surfaces for each tooth (Fig. 5). A profilometer (Talysurf CLI 1000; Taylor Hobson Precision, Japan) was used to measure the amount of surface loss in the samples. The output of the profilometer is the greatest difference in mean height as scanned by the stylus. The data were analyzed using SPSS version 24 software. A confidence level of $95 \%$ was set $(p<0.05)$, and one-way ANOVA along with post hoc test was used for comparison among the three groups.

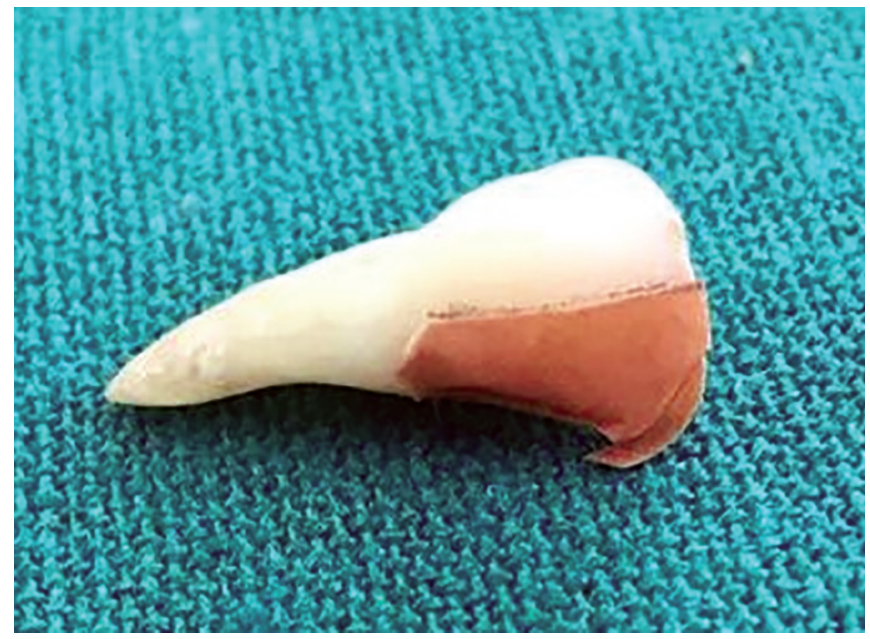

Fig. 1: Adhesive tape covering half the tooth surface

\section{Results}

Descriptive statistics of difference in mean height is shown in Table 1. Group III showed the greatest difference in mean height of $8.151 \mu \mathrm{m}$ followed by group I $(5.543 \mu \mathrm{m})$ and group II (3.509 $\mu \mathrm{m})$. Figure 6 represents the above results in the form of a bar diagram. One-way ANOVA showed that there was a statistically significant difference in the surface loss among the groups $(p=0.001)$. Therefore, a post hoc analysis was done for intragroup comparison, and it revealed that the erosive effect in both groups I and II was significantly less than in group III (control group), while erosive effect in group II (sodium fluoride mouthwash) was significantly less than in group I (CPP-ACP-F paste; Table 2).

\section{Discussion}

Dental erosion is the area of localized loss of chemically etched hard dental tissue from the surface of the tooth by acid dissolution without bacterial involvement. ${ }^{8}$ Consumption of soft drinks has often been identified as one of the most significant risk factors for dental erosion. ${ }^{9}$ As lifestyles have changed, soft drink consumption has increased by $50 \%$ over the past few decades, especially among children and adolescents. ${ }^{10}$ Among the soft drinks, Cola drink has the highest erosive potential, and this was the rationale for using it in this study. ${ }^{11,12}$

The intention of preventive therapy for dental erosions is to modify the tooth surface by enhancing its resistance against acids. The most widely recommended method for inhibition of demineralization is regular and frequent application of fluoride preparations. Fluorides influence the equilibrium between demineralization and remineralization of teeth in two ways. First, the fluoride ions inside the bacterial biofilm increase the critical pH for $\mathrm{Ca}$ and $\mathrm{PO}_{4}$ dissolution. Second, the fluorides form chemically stable fluorapatite crystals in the enamel structure, thereby reducing its acid solubility. ${ }^{13}$

The fluoride uptake is influenced by the concentration of calcium and phosphate ions in the saliva or biofilm. One unit cell of fluorapatite $\left[\mathrm{Ca}_{10}\left(\mathrm{PO}_{4}\right)_{6} \mathrm{~F}_{2}\right]$ is formed from 10 calcium ions and 6 phosphate ions along with 2 fluoride ions. Thus, topical applications of calcium and phosphate complexes such as CPP-ACP-F toothpaste release minerals such as $\mathrm{Ca}^{2+}$ and $\mathrm{PO}_{4}{ }^{3-}$ ions along with fluoride ions under an acid challenge to supersaturate the saliva and help in remineralization. ${ }^{14}$

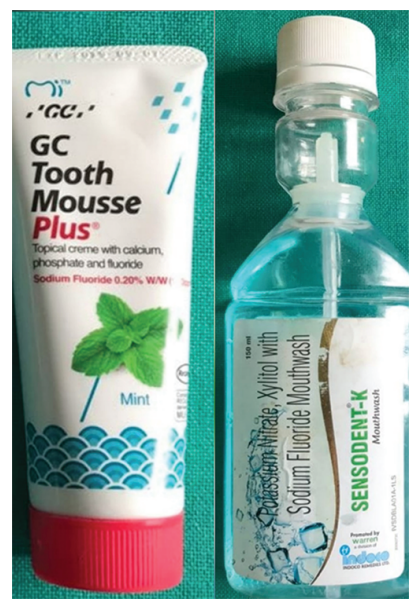

Fig. 2: GC TM plus and Sensodent K used for pretreatments in group I and group II 

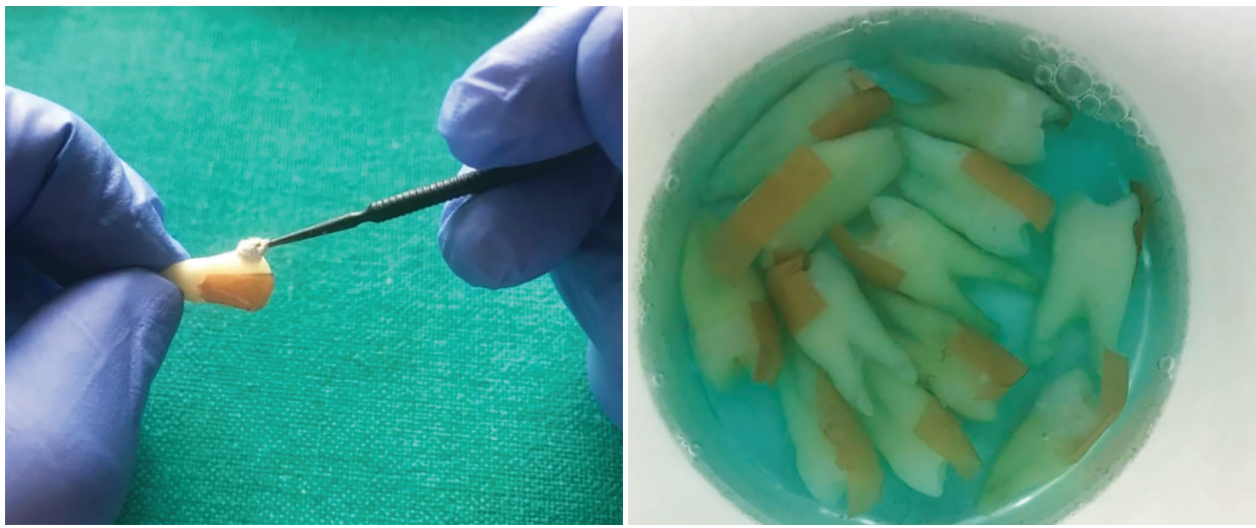

Fig. 3: Casein phosphopeptide-amorphous calcium phosphate-fluoride paste applied on the exposed half of the tooth in group I and the samples of group II immersed in sodium fluoride mouthwash

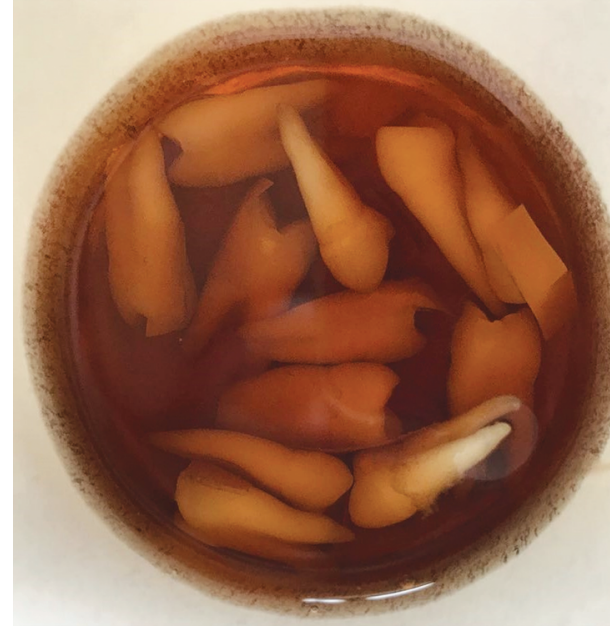

Fig. 4: Samples exposed to acidic beverages

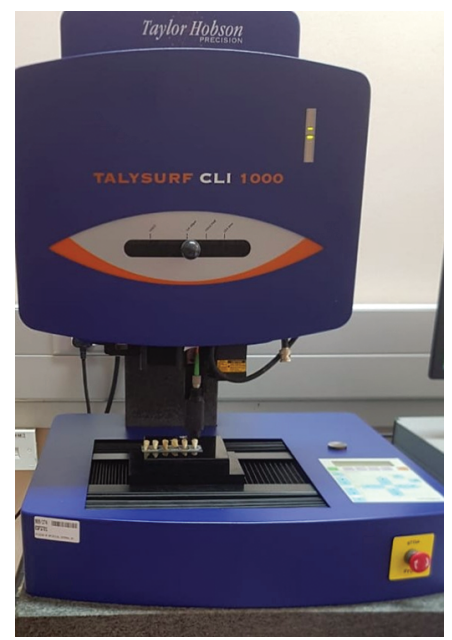

Fig. 5: Surface loss measured using profilometer

Table 1: Descriptive statistics of difference in mean height among the three groups

\begin{tabular}{llllll}
\hline Groups & $n$ & Minimum $(\mu \mathrm{m})$ & Maximum $(\mu \mathrm{m})$ & Mean $(\mu \mathrm{m})$ & Standard deviation $(\mu \mathrm{m})$ \\
\hline Group I & 12 & 4.205 & 6.55 & 5.543 & 0.635 \\
Group II & 12 & 2.08 & 4.477 & 3.509 & 0.667 \\
Group III & 12 & 7.3 & 9.02 & 8.151 & 0.557 \\
\hline
\end{tabular}

Erosion can be quantified by measuring the surface roughness. The most frequently adopted techniques for analyzing the erosively altered dental hard tissues are profilometry, microradiography, scanning electron microscopy, atomic force microscopy, nano and microhardness tests, and iodide permeability test. ${ }^{15}$ Profilometry has been shown as a highly accurate method for the measurement of surface loss by various researchers. ${ }^{16}$

In this study, sodium fluoride mouthwash showed marked efficacy in the prevention of erosion than CPP-ACP-F paste and control group. Moezizadeh and Alimi ${ }^{17}$ in their study compared the efficacy of CPP-ACP paste and sodium fluoride mouthwash for the prevention of erosion and found that sodium fluoride mouthwash was the most effective anti-erosive agent. This could be attributed to the increase in the concentration of fluoride ion as deep as $40 \mu$ in dentin leaving behind a fluoride reservoir in deeper dentinal layers. ${ }^{18}$ Wegehaupt and Attin ${ }^{19}$ observed in their study that the daily application of $\mathrm{NaF}$ or amine/NaF gels could reduce the tooth wear significantly when compared with the application of CPPACP-containing cream.

In this study, CPP-ACP-F paste group also showed its efficacy in the prevention of erosion than the control group in accordance with the findings of Jayarajan et al., ${ }^{20}$ where CPP-ACP-F showed marginally more amount of remineralization than CPP-ACP due to the added benefit of fluoride. This study also revealed that the surface loss was more than the sodium fluoride mouthwash group which could be attributed to the localization of calcium and phosphate ions with the fluoride ions at the enamel surface without involving the deeper dentinal layers. ${ }^{21}$ This could be also due to the decreased duration of exposure, i.e., 5 days in this study. In addition, this study was conducted in the absence of an oral microbial environment or plaque accumulation on the tooth surfaces that may have resulted in reduced CPP-ACP-F adherence to tooth surfaces since CPP-ACP-F has been suggested to be incorporated into the plaque by binding to bacterial cell surfaces and intercellular plaque matrix. ${ }^{22}$ 


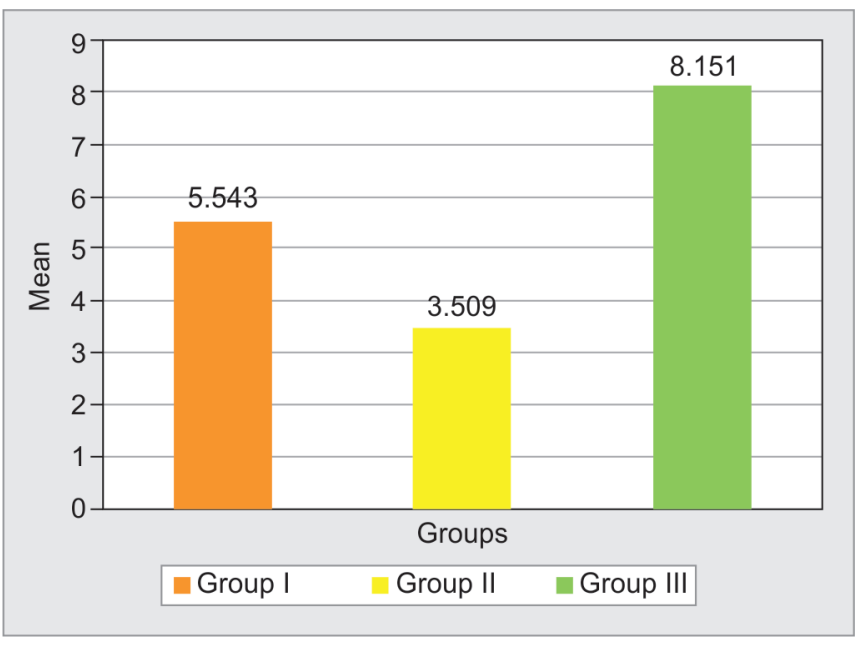

Fig. 6: Bar diagram showing surface loss among the three groups

Table 2: Post hoc analysis for multiple comparisons among groups I, II, and III

\begin{tabular}{lllll}
\hline & & \multicolumn{2}{l}{ Mean difference } \\
(I) Group & (J) Group & $\begin{array}{l}\text { Standard } \\
\text { (I-Jror }\end{array}$ & Significance \\
\hline Group I & Group II & 2.03375 & 0.253617 & 0.001 \\
& Group III & -2.60786 & 0.253617 & 0.001 \\
Group II & Group I & -2.03375 & 0.253617 & 0.001 \\
& Group III & -4.64162 & 0.253617 & 0.001 \\
Group III & Group I & 2.60786 & 0.253617 & 0.001 \\
& Group II & 4.64162 & 0.253617 & 0.001 \\
\hline
\end{tabular}

Although both CPP-ACP-F paste and sodium fluoride mouthwash are effective as anti-erosion agents, sodium fluoride mouthwash showed more influence on the prevention of surface loss than CPP-ACP-F paste in this study. CPP-ACP-F paste may enhance remineralization provided there is more duration of exposure. However, further studies are needed to know the morphological changes of tooth substrates at in vivo conditions.

\section{ConcLusion}

Both sodium fluoride mouthwash and CPP-ACP-F pastes are effective methods for the prevention of erosion for at-risk patients. Within the limitations of this study, it can be concluded that sodium fluoride mouthwash has better results. By strengthening the tooth enamel surface, they provide protection against caries and prevent erosive tooth wear.

\section{References}

1. Imfeld T. Dental erosion: definition, classification and links. Eur J Oral Sci 1996;104(2(Pt 2)):151-155. DOI: 10.1111/j.1600-0722.1996. tb00063.x.

2. Schlossman M, Montana M. Preventing damage to oral hard and soft tissues. In: Spolarich AE, Panagakos FS. Prevention Across the Lifespan: A Review of Evidence-Based Interventions for Common Oral Conditions. Charlotte: Professional Audience Communications, Inc.; 2017. pp. 97-120.

3. Featherstone JD. The science and practice of caries prevention. J Am Dent Assoc 2000;131(7):887-899. DOI: 10.14219/jada. archive.2000.0307.
4. Salas MM, Nascimento GG, Vargas-Ferreira F. Diet influenced tooth erosion prevalence in children and adolescents: Results of a metaanalysis and meta-regression. J Dent 2015;43(8):865-875. DOI: 10.1016/j.jdent.2015.05.012.

5. Wiegand A, Attin T. Influence of fluoride on the prevention of erosive lesions - a review. Oral Health Prev Dent 2003;1(4):245-253.

6. Bayrak S, Tuloglu N, Bicer H, et al. Effect of fluoride varnish containing CPP-ACP on preventing enamel erosion. Scanning 2017;2017. DOI: 10.1155/2017/1897825.

7. Thakkar PJ, Badakar CM, Hugar SM, et al. An in vitro comparison of casein phosphopeptide-amorphous calcium phosphate paste, casein phosphopeptide-amorphous calcium phosphate paste with fluoride and casein phosphopeptide-amorphous calcium phosphate varnish on the inhibition of demineralization and promotion of remineralization of enamel. J Indian Soc Pedod Prev Dent 2017;35(4):312. DOI: 10.4103/JISPPD.JISPPD_308_16.

8. Tantbirojn $D$, Huang A, Ericson MD, et al. Change in surface hardness of enamel by a cola drink and a CPP-ACP paste. J Dent 2008;36(1): 74-79. DOI: 10.1016/j.jdent.2007.10.008.

9. Jensdottir T, Bardow A, Holbrook P. Properties and modification of soft drinks in relation to their erosive potential in vitro. J Dent 2005;33(7):569-575. DOI: 10.1016/j.jdent.2004.12.002.

10. Rirattanapong $P$, Vongsavan $K$, Suratit $R$, et al. Effect of various forms of calcium in dental products on human enamel microhardness in vitro. Southeast Asian J Trop Med Public Health 2012;43(4): 1053-1058.

11. Jensdottir $T$, Holbrook $P$, Nauntofte $B$, et al. Immediate erosive potential of cola drinks and orange juices. J Dent Res 2006;85(3): 226-230. DOI: 10.1177/154405910608500304.

12. Torres CP, Chinelatti MA, Gomes-Silva JM, et al. Surface and subsurface erosion of primary enamel by acid beverages over time. Braz Dent J 2010;21(4):337-345. DOI: 10.1590/S0103-64402010000400009.

13. Ten Cate JM. Current concepts on the theories of the mechanism of action of fluoride. Acta Odontol Scand 1999;57(6):325-329. DOI: 10.1080/000163599428562.

14. Carounanidy U, Sathyanarayanan R. Dental caries: a complete changeover, PART III: changeover in the treatment decisions and treatments. J Conserv Dent 2010;13(4):209-217. DOI: 10.4103/09720707.73383.

15. Attin T. Methods for assessment of dental erosion. Monogr Oral Sci 2006;20:152-172.

16. Wiegand A, Meier W, Sutter E, et al. Protective effect of different tetrafluorides on erosion of pellicle-free and pellicle-covered enamel and dentine. Caries Res 2008;42(4):247-254. DOI: 10.1159/ 000135669.

17. Moezizadeh M, Alimi A. The effect of casein phosphopeptideamorphous calcium phosphate paste and sodium fluoride mouthwash on the prevention of dentine erosion: an in vitro study. J Conserv Dent 2014;17(3):244-249. DOI: 10.4103/0972-0707.1 31787.

18. Wiegand A, Hiestand B, Sener B, et al. Effect of TiF ${ }_{4}, \mathrm{ZrF}_{4}, \mathrm{HfF}_{4}$ and $\mathrm{AmF}$ on erosion and erosion/abrasion of enamel and dentin in situ. Arch Oral Biol 2010;55(3):223-228. DOI: 10.1016/j.archoralbio.2009.11.007.

19. WegehauptFJ, Attin T.The role of fluoride and casein phosphopeptide/ amorphous calcium phosphate in the prevention of erosive/abrasive wear in an in vitro model using hydrochloric acid. Caries Res 2010;44(4):358-363. DOI: 10.1159/000316542.

20. Jayarajan J, Janardhanam P, Jayakumar P. Efficacy of CPP-ACP and CPP-ACPF on enamel remineralization-an in vitro study using scanning electron microscope and diagnodent. Indian J Dent Res 2011;22(1):77-82. DOI: 10.4103/0970-9290.80001.

21. Wang $X$, Megert $B$, Hellwig $E$, et al. Preventing erosion with novel agents. J Dent 2011;39(2):163-170. DOI: 10.1016/j.jdent.2010.11.007.

22. Trairatvorakul C, Kangvansurakit N, Pathomburi J. In vitro comparison of self versus professionally applied remineralizing materials. J Clin Pediatr Dent 2010;34(4):323-328. DOI: 10.17796/jcpd.34.4.p35436j0 $5010 u 562$. 